\title{
Functional mapping of hospitals by diagnosis-dominant case-mix
} analysis

\author{
Kiyohide Fushimi*1, Hideki Hashimoto2, Yuichi Imanaka3, \\ Kazuaki Kuwabara ${ }^{4}$, Hiromasa Horiguchi ${ }^{2}$, Kohichi B Ishikawa ${ }^{5}$ and \\ Shinya Matsuda ${ }^{6}$
}

\begin{abstract}
Address: ${ }^{1}$ Department of Health Care Informatics, Tokyo Medical and Dental University Graduate School, Tokyo, Japan, ${ }^{2}$ Department of Health Management and Policy, The University of Tokyo Graduate School of Medicine, Tokyo, Japan, ${ }^{3}$ Department of Healthcare Economics and Quality Management, Kyoto University Graduate School of Medicine, Kyoto, Japan, ${ }^{4}$ Department of Health Care Administration and Management, Kyushu University Graduate School of Medical Science, Fukuoka, Japan, ${ }^{5}$ Cancer Information and Epidemiology Division, National Cancer Center Research Institute, Tokyo, Japan and ${ }^{6}$ Department of Preventive Medicine and Community Health, University of Occupational and Environmental Health, Fukuoka, Japan

Email: Kiyohide Fushimi* - kfushimi.hci@tmd.ac.jp; Hideki Hashimoto - hidehashimoto-circ@umin.ac.jp;

Yuichi Imanaka - imanaka@pbh.med.kyoto-u.ac.jp; Kazuaki Kuwabara - kazu228@basil.ocn.ne.jp; Hiromasa Horiguchi - hiromasatky@umin.ac.jp; Kohichi B Ishikawa - kishikaw@ncc.go.jp; Shinya Matsuda - smatsuda@med.uoeh-u.ac.jp

* Corresponding author
\end{abstract}

Published: 10 April 2007

BMC Health Services Research 2007, 7:50 doi:10.1 I86//472-6963-7-50

Received: 3I August 2006

Accepted: 10 April 2007

This article is available from: http://www.biomedcentral.com/I472-6963/7/50

(C) 2007 Fushimi et al; licensee BioMed Central Ltd.

This is an Open Access article distributed under the terms of the Creative Commons Attribution License (http://creativecommons.org/licenses/by/2.0), which permits unrestricted use, distribution, and reproduction in any medium, provided the original work is properly cited.

\begin{abstract}
Background: Principles and methods for the allocation of healthcare resources among healthcare providers have long been health policy research issues in many countries. Healthcare reforms including the development of a new case-mix system, Diagnosis Procedure Combination (DPC), and the introduction of a DPC-based payment system are currently underway in Japan, and a methodology for adequately assessing the functions of healthcare providers is needed to determine healthcare resource allocations.

Methods: By two-dimensional mapping of the rarity and complexity of diagnoses for patients receiving treatment, we were able to quantitatively demonstrate differences in the functions of different healthcare service provider groups.

Results: On average, inpatients had diseases that were 3.6-times rarer than those seen in outpatients, while major teaching hospitals treated inpatients with diseases 3.0-times rarer on average than those seen at small hospitals.

Conclusion: We created and evaluated a new indicator for DPC, the diagnosis-dominant case-mix system developed in Japan, whereby the system was used to assess the functions of healthcare service providers. The results suggest that it is possible to apply the case-mix system to the integrated evaluation of outpatient and inpatient healthcare services and to the appropriate allocation of healthcare resources among health service providers.
\end{abstract}




\section{Background}

In order to effectively provide a variety of healthcare services, many countries are striving to devise new healthcare policies aimed at assigning appropriate roles, ensuring mutual cooperation among various healthcare service providers, appropriately allocating healthcare resources, and evaluating healthcare service providers [1-4].

For more than 30 years, Japan has maintained a nationwide social health insurance system of the Bismarck type. Almost the entire population of Japan is covered by this system, and it is financed by premiums paid by insured persons and employers, and government compensation. The system in Japan is similar to the German system that was first introduced by Bismarck. On the provider side, the majority of clinics and hospitals are private, though for-profit organisations are not allowed to own or manage hospitals and clinics. The relatively low-cost universal health insurance system of Japan is recognised globally as a major achievement [5]. However, the Japanese system compares unfavourably with those in other developed countries in terms of the inefficiency of healthcare service delivery, as reflected by long hospital stays of more than 20 days as compared to only 6.7 days on average for Organisation for Economic Co-operation and Development (OECD) countries [6]. In addition, the specialist healthcare service provider system has been criticised for being poorly organised with non-systematic delivery of services, as evidenced by the glut of expensive diagnostic equipment such as computed tomography scanners and magnetic resonance imaging units. The number of these devices per 100,000 population is more than five times the average of OECD countries [6].

In Japan, health policy measures have attempted to assign suitable roles and promote cooperation between primary care and specialist healthcare services, based on hospital bed regulations according to regional healthcare programs and incentives via medical service fees [7-9]. However, to date, these attempts have failed to assure the effectiveness of this approach. In this study, we used the Diagnosis Procedure Combination (DPC) case-mix system [10-12] recently developed in Japan to quantitatively analyse differences in outpatient and inpatient healthcare functions according to the type of medical institution. Our aim was to elucidate differences in function among hospitals by using case-mix-based indicators and to examine the possibilities of applying such indicators to health resource allocation in Japan. In evaluating medical institution functions, our study includes the complexity of the patient case mix previously used in such analyses as well as evaluation of the rarity of the case mix, which allows us to assess the provision of healthcare for a wide-range of diseases, including rare conditions for which clinical research or clinical training is vital at teaching hospitals $[13,14]$.

\section{Methods}

We assigned DPC codes for 591 diagnostic categories to the International Statistical Classification of Diseases and Related Health Problems 10th Revision codes for the primary diagnoses of patients in the 1.2 million records of the Patient Survey conducted in 2002 in Japan [15]. DPC is a diagnosis-dominant case-mix system, comprised of 591 higher order disease categories [see Additional file 1] and includes approximately 2,500 lower order categories, such as procedures, co-morbidities and complications. The Patient Survey is conducted every three years and the data for 2002 are the most recently available. In this survey, $70 \%$ of hospitals and $7 \%$ of clinics were randomly selected for investigation. The number and clinical features of patients discharged from the target facilities during the specified month, and those of patients who visited or stayed at the target hospitals on the specified day are reported. The outpatients are defined as those who did not use hospital beds: those receiving ambulatory surgeries, day treatments, consultations, follow-up visits and radiology tests are counted as outpatients. As primary and advanced cares are not clearly distinguished in Japan and there is virtually no difference between private and public facilities in terms of health services, it is reasonable to assume that all patients are included in this survey and that the data are representative of the entire population of Japan.

We defined the rarity index (Ri) of a DPC diagnostic category as the common logarithm of the relative number of patients [16] who were receiving medical care for a disease in that DPC diagnostic category as follows:

$R i_{D P C}=\log _{10}\left(p_{D P C}\right)$,

where $R i_{D P C}$ is the rarity index for a DPC category and $p_{D P C}$ is the relative number of patients who were receiving medical care for a disease in that DPC diagnostic category in Japan. The complexity index (Ci) of a DPC diagnostic category was defined as the relative value of the total admission fee per admission for patients who received inpatient care for a disease in that DPC diagnostic category, which we calculated from the DPC payment schedule [10]. We classified $\mathrm{Ri}$ and $\mathrm{Ci}$, calculated for inpatient and outpatient groups for each of the healthcare facilities, as follows: major teaching hospitals (MTH) consisted of 80 university hospitals and two national centre hospitals, other teaching hospitals (OTH) of teaching hospitals other than $\mathrm{MTH}$, other public hospitals (OPH) of non-teaching public hospitals, large private hospitals (LPH) of non-teaching private hospitals with 400 or more beds, small private hospitals (SPH) of non-teaching private hospitals with 
less than 400 beds, and clinics (C) of healthcare facilities with 0 to 19 beds. The characteristics of the healthcare facility groups in Japan are shown in Table 1. It should be noted that most hospitals in Japan provide considerable outpatient care and that some clinics have small inpatient facilities $[7,9]$. The averages of $\mathrm{Ri}$ and $\mathrm{Ci}$ for each healthcare facility group were calculated as follows:

$R i_{G}=\frac{1}{n_{G}} \sum^{n_{G}} R i_{D P C}, \quad C i_{G}=\frac{1}{n_{G}} \sum^{n_{G}} C i_{D P C}$

where $R i_{G}$ and $C i_{G}$ are the average values of Ri and $C i$ for the facility group $G$, respectively, $n_{G}$ is the number of patients in the facility group $\mathrm{G}_{\text {, and }} R i_{D P C}$ and $R i_{D P C}$ are $\mathrm{Ri}$ and Ci of the DPC category for each patient in the facility group G.

All statistical analyses were performed using Stata 8.0 SE and the level of significance was set at $\mathrm{p}<0.05$.

\section{Results}

The Ri and Ci of the 591 DPC diagnostic categories ranged from 0.87 to 7.53 and 0.12 to 7.57 , respectively. Among the 591 DPC categories, Ci was very weakly correlated with $\mathrm{Ri}$, with a regression coefficient of 0.15 and adjusted R-square of 0.066 , indicating very weak correlation between utilization of health care resources for treatment of a disease and the rarity of that disease.

We defined rare diseases as those comprising the first third of patients in the order of rarity, while intermediate diseases accounted for the second third, and common diseases the last one third. We made comparisons among these groups. The DPC disease category names for each rarity group are summarised in Table 2 . The most common diseases in Japan were as follows: hypertensive disease without organ damage $(\mathrm{Ri}=0.865)$, type 2 diabetes (excluding diabetic ketoacidosis) and diabetes not elsewhere classified $(\mathrm{Ri}=1.326)$, cataract and other disorders of the lens $(\mathrm{Ri}=1.360)$, metabolic disorders other than diabetes mellitus such as hyperlipidemia $(\mathrm{Ri}=1.466)$, and asthma $(\mathrm{Ri}=1.501)$.
Then, case-mix differences in terms of rarity among the hospital groups in Japan were examined (Table 2). The ratios of patients with each category of diseases differed significantly among the hospital groups $(\mathrm{p}<0.001)$. Rare diseases were more frequently observed with outpatient than with inpatient care. Among the hospital groups, rare diseases were prominent in MTH and OTH whereas common diseases were prominent in $\mathrm{C}$, for both inpatient and outpatient care. Our results suggest that the case-mix differs markedly among hospital groups, suggesting substantial differences in functionality. In addition, it was shown that teaching hospitals provide health care services to patients with rarer diseases than other hospitals in both the inpatient and the outpatient setting.

The averages for the $\mathrm{Ri}$ and $\mathrm{Ci}$ of inpatient and outpatient care for each healthcare facility group in Japan are summarised in Table 3 and Figure 1. The average values for Ri and $\mathrm{Ci}$ were 1.92 and 0.80 among all outpatients, and 2.48 and 1.00 among all inpatients, respectively, indicating that patients with more complex and rarer diseases tended to be hospitalised and that hospitalised patients had diseases that were $3.6\left(=10^{0.56}\right)$-times less frequently observed on average than those of outpatients.

The teaching hospitals were shown to provide health care services to inpatients with relatively rare diseases. The diseases of patients admitted to MTH were $3.0\left(=10^{0.479}\right)$ times rarer on average than those of patients admitted to $\mathrm{SPH}$. The averages of the Ri differed significantly among MTH, OTH, OPH and LPH, whereas those for LPH, SPH and $\mathrm{C}$ were rather similar. Our results may suggest that there are four functionally different groups, i.e. private and public facilities and two types of teaching hospitals, in terms of the rarity of diseases in the inpatient care setting in Japan. Our results also showed that teaching hospitals provide more complex services than other facilities. However, the differences in $\mathrm{Ci}$ among the facility groups were not as distinct as those for Ri, indicating that the Ri may more clearly illustrate differences in hospital function than the Ci.

Table I: Characteristics of healthcare facility groups in Japan

\begin{tabular}{lcccc}
\hline & Number of facilities & $\begin{array}{c}\text { Average length of hospital } \\
\text { stay (Days) }\end{array}$ & $\begin{array}{c}\text { Average number of beds } \\
\text { per facility }\end{array}$ & $\begin{array}{c}\text { Total number of } \\
\text { outpatients per day (I000 } \\
\text { visits) }\end{array}$ \\
\hline Major teaching hospital & 165 & 24.1 & 543 & 180 \\
Other teaching hospital & 337 & 21.8 & 507 & 354 \\
Other public hospital & 1,786 & 24.5 & 197 & 599 \\
Large private hospital & 683 & 27.1 & 230 & 75 \\
Small private hospital & 5,161 & 28.0 & 2 & 573 \\
Clinic & 96,305 & 17.6 & 3,351
\end{tabular}


Table 2: Case-mix difference by rarity index among healthcare facility groups in Japan

\begin{tabular}{|c|c|c|c|c|c|}
\hline & & & \multicolumn{3}{|c|}{ Disease categories by rarity index } \\
\hline & & & Rare diseases & Intermediate diseases & Common diseases \\
\hline Rarity index & & & $2.20-7.53$ & $1.60-2.15$ & $0.87-1.59$ \\
\hline $\begin{array}{l}\text { DPC disease category } \\
\text { name (excerpts) }\end{array}$ & & & $\begin{array}{l}\text { Pheochromocytoma, paraganglioma; } \\
\text { Malignant cardiac tumour; } \\
\text { Tuberculous meningitis, } \\
\text { meningoencephalitis; Acquired } \\
\text { deformation of femur; Orbital tumour }\end{array}$ & $\begin{array}{l}\text { Malignant breast tumour; Tachycardic } \\
\text { arrhythmia; Malignant gastric tumour; } \\
\text { Chronic sinusitis; Rheumatoid } \\
\text { arthritis of upper limb (from shoulder } \\
\text { to hand) }\end{array}$ & $\begin{array}{l}\text { Hypertensive disease (without organ } \\
\text { damage); Type } 2 \text { diabetes (excluding } \\
\text { diabetic ketoacidosis) and diabetes } \\
\text { not elsewhere classified*; Cataract } \\
\text { and other disorders of the lens; } \\
\text { Metabolic disorders other than } \\
\text { diabetes mellitus; Asthma }\end{array}$ \\
\hline \multirow{12}{*}{$\begin{array}{l}\text { Ratio of patients with each } \\
\text { disease category for each } \\
\text { group of facilities } \ddagger \text { (\%) }\end{array}$} & Inpatient $\nmid$ & MTH & $79.9(79.5-80.3)$ & $15.2(14.9-15.6)$ & $4.8(4.6-5.1)$ \\
\hline & & ОTH & $74.4(74.1-74.7)$ & $19.7(19.4-20.0)$ & $5.9(5.7-6.1)$ \\
\hline & & $\mathrm{OPH}$ & $68.1(67.8-68.4)$ & $26.4(26.2-26.6)$ & $5.5(5.4-5.6)$ \\
\hline & & LPH & $55.5(55.1-55.9)$ & $39.8(39.4-40.2)$ & $4.7(4.6-4.9)$ \\
\hline & & $\mathrm{SPH}$ & $54.1(53.8-54.3)$ & $40.6(40.3-40.8)$ & $5.4(5.2-5.5)$ \\
\hline & & C & $49.2(48.0-50.4)$ & $39.3(38.1-40.4)$ & $11.5(10.8-12.3)$ \\
\hline & Outpatient $\uparrow$ & MTH & $58.0(57.6-58.4)$ & $29.9(29.5-30.2)$ & $12.2(11.9-12.4)$ \\
\hline & & OTH & $52.2(51.9-52.5)$ & $31.9(31.7-32.2)$ & $15.8(15.6-16.1)$ \\
\hline & & $\mathrm{OPH}$ & $44.9(44.6-45.1)$ & $34.7(34.5-35.0)$ & $20.4(20.2-20.6)$ \\
\hline & & $\mathrm{LPH}$ & $40.4(39.9-41.0)$ & $38.7(38.2-39.3)$ & $20.8(20.4-21.3)$ \\
\hline & & $\mathrm{SPH}$ & $36.9(36.5-37.3)$ & $39.0(38.6-39.3)$ & $24.1(23.8-24.4)$ \\
\hline & & $\mathrm{C}$ & $28.6(28.4-28.8)$ & $39.6(39.4-39.8)$ & $31.8(31.6-32.0)$ \\
\hline
\end{tabular}

DPC: Diagnosis-procedure combination, MTH: Major teaching hospital, OTH: Other teaching hospital, OPH: Other public hospital, LPH: Large private hospital, SPH: Small private hospital, C: Clinic

*DPCI 00070 for Type 2 Diabetes Mellitus (DM) and DPCI00340 for Other DM were analysed as one category in this study.

† Pearson's chi-squared test: $p<0.001$ both for inpatients and outpatients

$\ddagger$ Mean (Confidence interval)

We also recognised a significant difference in the rarity of outpatient care among the facility groups. There was a 3.6 $\left(=10^{0.561}\right)$-fold difference in the Ri of diseases between MTH and C. On the contrary, in view of complexity, only $\mathrm{C}$ had a significantly different profile. Our results clearly demonstrate outpatients visiting clinics to have less complex and more frequently observed diseases than the outpatients visiting hospitals, indicating that outpatient function differs markedly between clinics and hospitals.

Figure 1 suggests a positive correlation between $\mathrm{Ri}$ and $\mathrm{Ci}$ among the facility groups. However, when examined together with Table 2, it becomes apparent that there are several differences between $\mathrm{Ri}$ and $\mathrm{Ci}$ in describing the functions of the six facility groups. For inpatient care, Ri appears to have greater power to discriminate functional differences among the facility groups because most of the differences between each pair of groups were statistically significant. We emphasise especially the Ri difference between the public and private hospital groups in contrast to the $\mathrm{Ci}$ similarity of these groups. For outpatient care, although $\mathrm{Ci}$ was similar in all but the clinics, Ri differed significantly among the facility groups. The results suggest that $\mathrm{Ri}$ is superior to $\mathrm{Ci}$ in describing the functional differences in outpatient care. In terms of health resource allocation, public and private sectors with intermediate complexity use the majority of resources whereas teaching sectors with high rarity and complexity use less for inpatient care. Clinics consume nearly $60 \%$ of outpatient resources and resource amounts for the hospital groups were lower than for clinics.

\section{Discussion}

The analysis of complexity and rarity based on our casemix system clearly demonstrated differences in function between Japanese healthcare service provider groups. Regulations governing hospitals in Japan are quite lax, apart from those on bed numbers, and there are almost no policy regulations on the provision of specialised healthcare [7-9]. However, two-dimensional mapping based on complexity and rarity revealed the natural progression in functional specialisation for both outpatient and inpatient care, with various forms of specialised care being provided by clinics, non-teaching hospitals, and university hospitals.

Application of the case-mix system is a new approach to allocating healthcare resources. The DPC, as developed in Japan, provides a diagnosis-dominant disease classification system. DPC has a hierarchical classification system with diagnosis at the top level, procedures at the second, and co-morbidities and complications at the third. When DPC is used to determine the price for inpatient care, cases are classified using all three levels of the DPC classification, which results in approximately 2500 groupings. We assume that when DPC is applied to global resource allocation, since a simpler classification is required, only the diagnostic groupings at the top level can be used. This 
Table 3: Differences in rarity and complexity among hospital groups in Japan

\begin{tabular}{|c|c|c|c|c|c|c|c|}
\hline & & \multicolumn{6}{|c|}{ Healthcare facility groups } \\
\hline & & MTH & ОтН & $\mathrm{OPH}$ & LPH & SPH & C \\
\hline \multirow[t]{13}{*}{ In-patient } & Rarity index* & $2.82(2.75-2.88)$ & $2.66(2.59-2.72)$ & $2.57(2.50-2.63)$ & $2.35(2.28-2.42)$ & $2.34(2.27-2.40)$ & $2.36(2.26-2.45)$ \\
\hline & & - & $P=0.026$ vs. $M T H$ & $\mathrm{P}<0.00 \mathrm{I}$ vs. MTH & $\mathrm{P}<0.00 \mathrm{I}$ vs. MTH & $\mathrm{P}<0.00 \mathrm{I}$ vs. MTH & $\mathrm{P}<0.00 \mathrm{I}$ vs. MTH \\
\hline & & -- & -- & $p=0.049$ vs. OTH & $\mathrm{P}<0.00 \mathrm{I}$ vs. OTH & $\mathrm{P}<0.00 \mathrm{I}$ vs. OTH & $\mathrm{P}<0.001$ vs. OTH \\
\hline & & -- & -- & -- & $\mathrm{p}<0.001$ vs. $\mathrm{OPH}$ & $\mathrm{p}<0.001$ vs. $\mathrm{OPH}$ & $P=0.001$ vs. $O P H$ \\
\hline & & -- & -- & -- & -- & N.S. vs. LPH & N.S. vs. LPH \\
\hline & & -- & -- & -- & -- & -- & N.S. vs. SPH \\
\hline & Complexity index* & $1.14(1.09-1.20)$ & $1.06(1.01-1.11)$ & $1.00(0.96-1.05)$ & $1.02(0.97-1.07)$ & $0.98(0.94-1.03)$ & $0.88(0.83-0.93)$ \\
\hline & & -- & N.S. vs. MTH & $P=0.002$ vs. MTH & $\mathrm{P}=0.013$ vs. $\mathrm{MTH}$ & $\mathrm{P}<0.00 \mathrm{I}$ vs. MTH & $\mathrm{P}<0.00 \mathrm{I}$ vs. MTH \\
\hline & & -- & -- & N.S. vs. OTH & N.S. vs. OTH & $\mathrm{P}=0.015$ vs. OTH & $\mathrm{P}<0.001$ vs. ОTH \\
\hline & & -- & -- & -- & N.S. vs. OPH & N.S. vs. OPH & $P=0.010$ vs. $O P H$ \\
\hline & & -- & -- & -- & -- & N.S. vs. LPH & $P=0.005$ vs. $L P H$ \\
\hline & & -- & -- & -- & -- & -- & $p=0.023$ vs. SPH \\
\hline & $\begin{array}{l}\text { Relative healthcare } \\
\text { expenditure } \dagger\end{array}$ & 0.03 & 0.09 & 0.15 & 0.05 & 0.10 & 0.02 \\
\hline \multirow[t]{13}{*}{ Out-patient } & Rarity index* & $2.43(2.27-2.60)$ & $2.26(2.17-2.34)$ & $2.12(2.05-2.19)$ & $2.08(1.95-2.21)$ & $2.02(1.94-2.09)$ & $1.87(1.84-1.91)$ \\
\hline & & -- & N.S. vs. MTH & $\mathrm{P}<0.00 \mathrm{I}$ vs. MTH & $P=0.00 I$ vs. MTH & $\mathrm{P}<0.00 \mathrm{I}$ vs. MTH & $\mathrm{P}<0.00 \mathrm{I}$ vs. MTH \\
\hline & & -- & -- & $\mathrm{P}=0.021$ vs. OTH & $\mathrm{P}=0.033$ vs. OTH & $\mathrm{P}<0.00$ I vs. OTH & $\mathrm{P}<0.00 \mathrm{I}$ vs. ОTH \\
\hline & & -- & -- & -- & N.S. vs. OPH & $P=0.048$ vs. $\mathrm{OPH}$ & $\mathrm{P}<0.001$ vs. $\mathrm{OPH}$ \\
\hline & & -- & -- & -- & -- & N.S. vs. LPH & $p=0.003$ vs. $L P H$ \\
\hline & & -- & -- & -- & -- & & $\mathrm{p}<0.00 \mathrm{I}$ vs. SPH \\
\hline & Complexity index* & $0.87(0.77-0.97)$ & $0.82(0.76-0.87)$ & $0.81(0.77-0.86)$ & $0.81(0.73-0.89)$ & $0.83(0.78-0.88)$ & $0.75(0.73-0.77)$ \\
\hline & & - & N.S. vs. MTH & N.S. vs. MTH & N.S. vs. MTH & N.S. vs. MTH & $\mathrm{P}=0.020$ vs. $\mathrm{MTH}$ \\
\hline & & -- & -- & N.S. vs. OTH & N.S. vs. OTH & N.S. vs. OPH & $p=0.016$ vs. OTH \\
\hline & & -- & -- & -- & N.S. vs. OTH & N.S. vs. LPH & $p=0.011$ vs. $O P H$ \\
\hline & & -- & -- & -- & -- & N.S. vs. LPH & N.S. vs. OPH \\
\hline & & -- & -- & -- & -- & -- & $p=0.002$ vs. SPH \\
\hline & $\begin{array}{l}\text { Relative healthcare } \\
\text { expenditure } \dagger\end{array}$ & 0.02 & 0.05 & 0.08 & 0.02 & 0.06 & 0.33 \\
\hline
\end{tabular}

MTH: Major teaching hospital, OTH: Other teaching hospital, OPH: Other public hospital, LPH: Large private hospital, SPH: Small private hospital,

C: Clinic, N.S.: Not significant

*Mean (confidence interval) and $p$-values by Student's $t$ test

† Determined from results of the Survey of National Medical Care Insurance Services conducted in 2002 in Japan.

allows some unique applications which enhance our understanding of regional disease structures [11]. Furthermore, if some reduction in accuracy is feasible, outpatient and inpatient healthcare can be evaluated on a uniform scale.

Moreover, the DPC system allows novel analyses from the perspective of rarity as seen in this study. The evaluation of case-mix rarity may also be applicable to decision-making on the allocation of healthcare resources based on education and training, or advanced healthcare functions. It has been shown that most teaching and public hospitals, although they spend relatively more health care resources per patient than other facilities, tend to have a financing deficit in contrast to other hospitals and clinics in Japan. We consider inadequate resource allocation to probably be due to most health care organisations being financed according to basically the same fee-for-service payment schedule in Japan. In this scheme, as the incomes of hospitals are determined almost entirely by the quantity of health care services they provide, differences in case-mix rarity or complexity among these hospitals may not be reflected in their financing. Teaching hospitals are assumed to need more resources because they are required to provide teaching and research services in addition to clinical care. We speculate that the high Ri obtained herein for teaching hospitals may be related to these additional functions of teaching hospitals. Therefore, we anticipate that our case-mix-based approach will improve assessment of the needs for health care resources in teaching and public hospitals.

A comparison of inpatients of intermediate-level complexity at public and private medical institutions showed an equivalent patient complexity but the rarity of diseases of patients receiving treatment was higher at public medical institutions. This may suggest that the diagnosis and treatment of rare diseases requires higher level training as well more sophisticated diagnostic and other types of equipment, such that public medical institutions, where more funding is received through subsidies, are responsible for providing healthcare services for rare diseases. Among many studies regarding the effects of hospital ownership on quality, cost and clinical behaviours [1719], our findings may be related to the previous observation of mutual functional compensations between public and private sectors [20]. We speculate that the case-mix differences in private and public sectors reflect the roles 


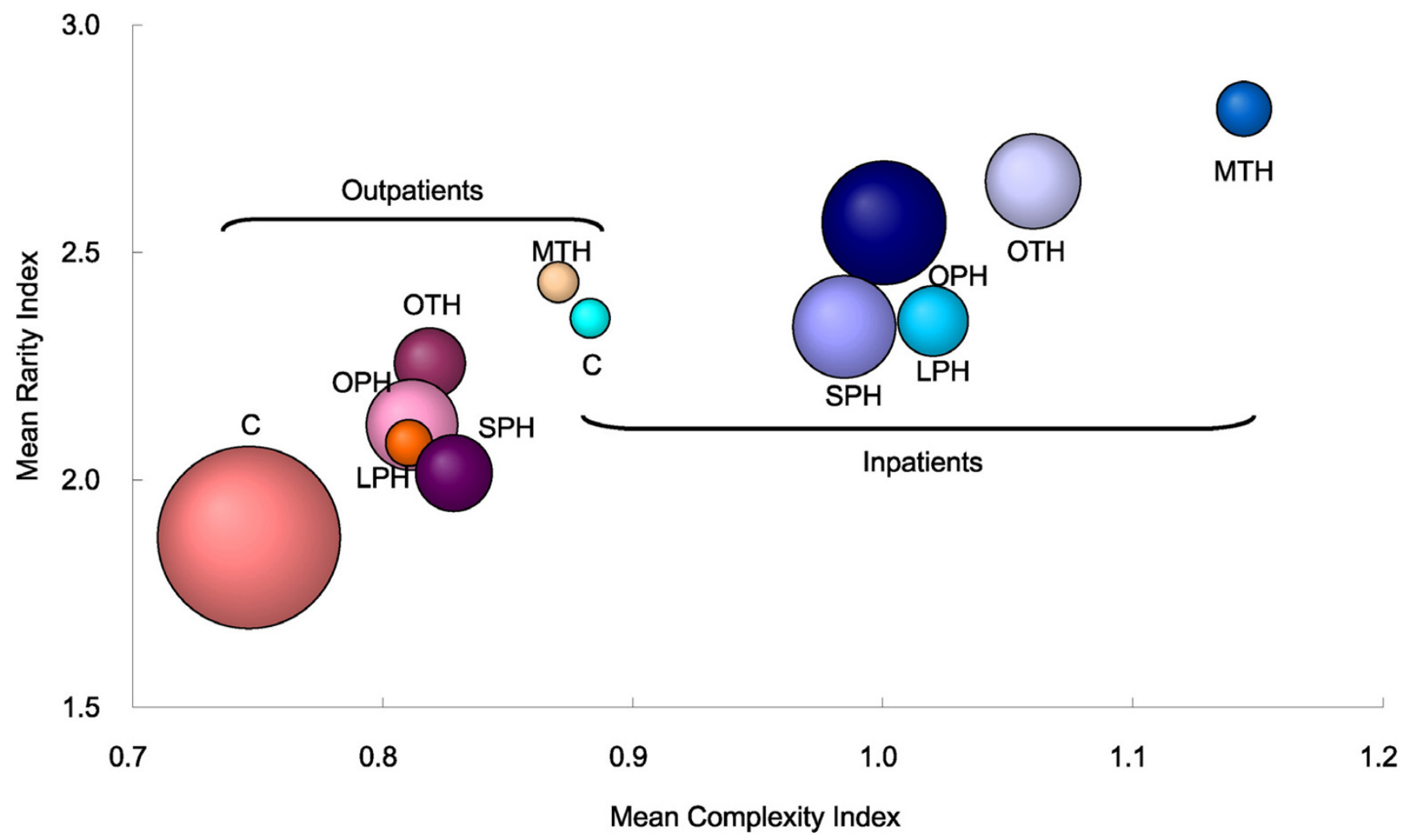

Figure I

Rarity and complexity indices for health care providers in Japan. Mean rarity index, mean complexity index, and relative healthcare expenditures for patients who received ambulatory care and inpatient care at major teaching hospitals (MTH), other teaching hospitals (OTH), other public hospitals (OPH), large private hospitals (LPH), small private hospitals (SPH) and clinics (C). The mean rarity index and mean complexity index per institution are shown. The size of the circle represents the relative healthcare expenditure as determined from the Survey of National Medical Care Insurance Services at 2002.

and the functions of those sectors. Most intractable diseases, including some congenital diseases, amyloidosis, severe collagen diseases and infectious diseases, are rare, and their diagnosis and treatment are anticipated to be more difficult and health-resource consuming than those for other diseases. Consequently, healthcare for patients with such diseases tends to be provided by public sectors or teaching hospitals in Japan.

As for outpatient care, our results showed that outpatient clinics, which consume approximately one third of total healthcare expenditures, have the lowest $\mathrm{Ri}$ and $\mathrm{Ci}$. Japan spends a higher proportion of its total healthcare budget on outpatient healthcare than other developed countries [5]. Although a shift of healthcare resources from inpatient to outpatient services may be one of the measures for improving the efficiency of healthcare systems, we consider the problem in Japan to be whether high outpatient costs counterbalance the quality of services in the outpatient sector. Our results may indicate that care for outpa- tients with complex and rare diseases is provided in the hospital rather than the clinic sector. Our case-mix analysis thus highlights the potential for healthcare policy research on the reallocation of healthcare resources, for example, by investigating the introduction of a capitation method in place of the current fee-for-service system. We speculate that a capitation-based payment system would be more suitable than the fee-for-service payment system, which is currently applied in Japan, as the incentives for efficient delivery of health care services are very poor with the latter system. We anticipate that investigations on the suitability of a capitation system, using our case-mixbased approach, might show such a payment system to be beneficial.

Many countries have adopted case-mix systems for hospital financing [21]. Health Care Financing AdministrationDiagnosis Related Groups (HCFA-DRG) or its derivatives have been used for developing a payment system in the USA as well as for adjustment of hospital budgeting in 
some countries including Belgium, France and Ireland. Our DPC differs from DRG systems in that DPC uses disease-oriented classification at its primary grouping level. When DPC is used for determining inpatient payments, groupings by procedures, co-morbidities and complications defined at the lower levels are utilised. The primary diagnosis-based level of DPC can be applied to describing the disease structure or case-mix profiling, such as the rarity of a disease, as shown in our study. Limitations of our approach may include its dependence on the rationality of case-mix classification logics.

Also, in terms of rarity assessment, the case-mix-based approach relies on the adequacy of the granularity of the grouping. We consider the grouping logics of DPC to be acceptable, because DPC was designed and has been maintained with consensus among specialist physician boards in Japan and it has in fact been applied to the payment system in acute care hospitals. In addition, we anticipate that the advantages of our method will overcome its limitations, although the use of a diagnosis domain without a procedure domain of DPC logics may lead to ambiguity in grouping logics.

\section{Conclusion}

We have provided one example of a method, using a casemix system, designed to clarify the differences among healthcare service provider functions based on differences in disease profiles among patients receiving treatment. This method allows a comprehensive evaluation of healthcare service provider functions, including inpatient and outpatient status, as well as teaching and research functions. It could therefore serve as a useful indicator for the appropriate allocation of healthcare resources among different healthcare service providers. It may be applicable to any financial measures including adjustments of hospital budgets, supplemental payments and subsidies.

\section{List of abbreviations}

$\mathrm{DPC}$, diagnosis-procedure combination; $\mathrm{Ri}$, rarity index; $\mathrm{Ci}$, complexity index; MTH, major teaching hospitals; OTH, other teaching hospitals; OPH, other public hospitals; LPH, large private hospitals; $\mathrm{SPH}$, small private hospitals; C, clinics; OECD, Organisation for Economic Cooperation and Development; HCFA-DRG, Health Care Financing Administration-Diagnosis Related Groups

\section{Competing interests}

The author(s) declare that they have no competing interests.

\section{Authors' contributions}

KF performed the quantitative analysis and drafted the manuscript, which was critically reviewed by all authors. SM and HH planned the study, and analysed and inter- preted the data. YI, KK, HH, KBI, and SS analysed and interpreted the data. All authors read and approved the final manuscript.

\section{Additional material}

\section{Additional file 1}

DPC Disease Category Definition Table. A PDF format file containing a table showing the DPC Category Code, DPC Disease Category Name, and ICD-10 codes classified according to each DPC category. Click here for file

[http://www.biomedcentral.com/content/supplementary/14726963-7-50-S1.pdf]

\section{Acknowledgements}

We are grateful to Masatsugu Taneichi and Fumie Miyoshi-Senoguchi for their database management and technical assistance, and to Kaori Ishii and Ritsuko Ohta for their clerical assistance. This study was funded in part by Grants-in-Aid for Research on Policy Planning and Evaluation and for Research on Applied Use of Statistics and Information from the Ministry of Health, Labour and Welfare, Japan. This work was conducted independently of those providing the funding.

\section{References}

I. McPake B, Mills A: What can we learn from international comparisons of health systems and health system reform? Bull World Health Organ 2000, 78:8II-820.

2. Kutzin J: A descriptive framework for country-level analysis of health care financing arrangements. Health Policy 200I, 56:17I-204.

3. Arah OA, Klazinga NS, Delnoij DM, ten Asbroek AH, Custers T: Conceptual frameworks for health systems performance: a quest for effectiveness, quality, and improvement. Int J for Qual Health Care 2003, I 5:377-398.

4. Blank RH, Burau V: Setting Priorities and Allocating Resources. In Comparative Health Policy New York: Palgrave MacMillan; 2004:87-121.

5. Blank RH, Burau V: Funding, Provision and Governance. In Comparative Health Policy New York: Palgrave MacMillan; 2004:59-86.

6. OECD Indicators 2005: Health at a Glance OECD Paris; 2005.

7. Ikegami N, Campbell JC: Medical care in Japan. New Engl J Med 1995, I 9:1295-1299.

8. Hirose M, Imanaka Y, Ishizaki T, Evans E: How can we improve the quality of health care in Japan? Learning from JCQHC hospital accreditation. Health Policy 2003, 66:29-49.

9. Fushimi K: Hospitals in Japan: A general perspective. Journal d'Économie Médicale 2004, 22:63-68.

10. Matsuda S, Fushimi K, Hashimoto $H$, Kuwabara K, Imanaka $Y$, Horiguchi H, Ishikawa KB, Anan M, Ueda K: The Japanese CaseMix Project: Diagnosis Procedure Combination (DPC). Proceedings of the 19th International Case Mix Conference PCS/E; 8-II October 2003; Washington, DC 2003:121-124

II. Fushimi K, Matsuda S: Application of DPC case-mix system and national patient data base to the arrangement of regional medical care plan and the estimation of health care expenditures in Japan. Proceedings of the 2 Ist International Case Mix Conference PCS/l; I I-I 4 October 2005; Ljubljana, Slovenia 2005:430-435.

12. Okamura S, Kobayashi R, Sakamaki T: Case-mix payment in Japanese medical care. Health Policy 2005, 74:282-286.

13. Green J, Passman LJ, Wintfeld N: Analyzing hospital mortality. The consequences of diversity in patient mix. JAMA 1991, 265: $1849-1853$

14. Jennings RM, Thompson LA, Townsend CL, Stashwick CA, Goodman DC: The relationship between pediatric residency program size and inpatient illness severity and diversity. Arch Pediatr Adolesc Med 2003, 157:676-680. 
15. Health and Welfare Statistics Association: Patient Survey 2002 (All Japan) Volume I Statistics and Information Department, Minister's Secretariat, Ministry of Health, Labour and Welfare, Japan. Tokyo; 2002.

16. Patil GP: Diversity Profiles. In Encyclopedia of Environmetrics Edited by: El-Shaarawi A, Piegorsch WW. UK: John Wiley \& Sons; 2002:555-56I.

17. Collins C, Green A: Public sector hospitals and organizational change: an agenda for policy analysis. Int J Health Plann Manage 1999, I 4:107-128.

18. Xirasagar S, Lin HC: Effects of payment incentives, hospital ownership and competition on hospitalization decisions for ambulatory surgical procedures. Health Policy 2006, 76:26-37.

19. Grilli R, Guastaroba P, Taroni F: Effect of hospital ownership status and payment structure on the adoption and use of drugeluting stents for percutaneous coronary interventions. CMAJ 2007, 176:185-190.

20. Brown L, Barnett JR: Is the corporate transformation of hospitals creating a new hybrid health care space? A case study of the impact of co-location of public and private hospitals in Australia. Soc Sci Med 2004, 58:427-444.

21. Roger France FH: Case mix use in $\mathbf{2 5}$ countries: a migration success but international comparisons failure. Int J Med Inform 2003, 70:215-219.

\section{Pre-publication history}

The pre-publication history for this paper can be accessed here:

http://www.biomedcentral.com/1472-6963/7/50/prepub

Publish with Bio Med Central and every scientist can read your work free of charge

"BioMed Central will be the most significant development for disseminating the results of biomedical research in our lifetime. "

Sir Paul Nurse, Cancer Research UK

Your research papers will be:

- available free of charge to the entire biomedical community

- peer reviewed and published immediately upon acceptance

- cited in PubMed and archived on PubMed Central

- yours - you keep the copyright 